\title{
Is intensive care monitoring necessary after coil embolization of unruptured intracranial aneurysms?
}

\author{
William R Stetler Jr, ${ }^{1}$ Julius Griauzde, ${ }^{2}$ Yamaan Saadeh, ${ }^{3}$ Thomas J Wilson, ${ }^{3}$ \\ Wajd N Al-Holou, ${ }^{3}$ Neeraj Chaudhary, ${ }^{2,3}$ B Gregory Thompson, ${ }^{2,3}$ Aditya S Pandey, ${ }^{2,3}$ \\ Joseph J Gemmete $2,3,4$
}

'Department of Neurosurgery, University of Florida, Gainesville, Florida, USA

${ }^{2}$ Departments of Radiology, University of Michigan, Ann Arbor, Michigan, USA ${ }^{3}$ Departments of Neurosurgery, University of Michigan, Ann Arbor, Michigan, USA

${ }^{4}$ Departments of Otolaryngology, University of Michigan, Ann Arbor, Michigan, USA

Correspondence to Dr Joseph J Gemmete, Department of Radiology, University of Michigan, $1500 \mathrm{E}$ Medical Center Drive, B1D530 University Hospital, SPC 5030, Ann Arbor, MI 48109-5030, USA; gemmete@med.umich.edu

Received 9 May 2016 Revised 17 June 2016 Accepted 20 June 2016 Published Online First 5 July 2016

\begin{abstract}
Introduction Patients with an unruptured intracranial aneurysm treated with coil embolization are routinely admitted to the intensive care unit (ICU) after the procedure; however, this practice is questionable. The purpose of this study was to determine if routine admission to the ICU is necessary for patients undergoing coil embolization of an unruptured intracranial aneurysm.
\end{abstract}

Methods We conducted a retrospective cohort study of all patients undergoing elective endovascular treatment of an unruptured intracranial aneurysm between 2005 and 2012 at our institution. Multivariate regression analysis was performed to identify predictors of outcome. Cost savings analysis compared ICU admission to step-down or telemetry unit admission.

Results 311 unruptured intracranial aneurysms were treated by coil embolization (190), balloon remodeling (13), or stent-assisted coiling (108). Eleven (3.5\%) neurologic complications were noted; $5(1.6 \%)$ of these were permanent. Multivariate regression analysis identified female sex $(p=0.028)$, hypercoagulability $(p=0.021)$, aneurysm size $>2 \mathrm{~cm}(p=0.003)$, and intraoperative rupture $(p<0.001)$ as predictors of a postprocedural neurologic complication. Cost savings were $57 \%$ for admission to a step-down unit and $32 \%$ for admission to a telemetry unit compared with ICU admission.

Conclusions Neurologic complications are rare in the treatment of unruptured intracranial aneurysms, suggesting that routine ICU admission after treatment may not be necessary. Female sex, history of hypercoagulability, aneurysm size $>2 \mathrm{~cm}$, and an intraprocedural rupture were predictive of a postoperative complication. ICU monitoring in these subgroups may therefore be warranted.

\section{INTRODUCTION}

Endovascular treatment of intracranial aneurysms is now safer and more effective, given improvements in medical therapy and endovascular technology following approval by the Food and Drug Administration of the first Guglielmi detachable coils in $1995 .^{1}$ Patients with unruptured intracranial aneurysms are now routinely placed on dual antiplatelet agents prior to treatment to reduce thromboembolic events. These medications reduce rates of thromboembolism and allow treatment of aneurysms previously not amenable to coil embolization through the placement of intracranial stents. $^{2-4}$ Today more aneurysms can be treated successfully, with a reduced risk of thromboembolic complications.

Limited data are available for elective surgical cases that mandate an intensive care unit (ICU) admission in the absence of hemodynamic or anesthetic complications. Several studies in the general surgical literature have shown reduced mortality, complications, and cost savings when using ICU for 'high-risk' surgical procedures; however, these studies have excluded neurosurgical cases. ${ }^{5-7}$ In the neurosurgical literature, retrospective case series have demonstrated success with selective use of the ICU, but reports conflict when neurovascular patient populations are analyzed, and there are no guidelines on whether unruptured intracranial aneurysms treated with coil embolization should be placed in the ICU following treatment. ${ }^{8-11}$ One study showed that postoperative placement to a regular floor unit may be safe in selected patients. ${ }^{12}$ Another study evaluated the safety and costeffectiveness of an immediate care step-down unit for patients after uncomplicated neurointerventional procedures. ${ }^{11}$

The purpose of our study was to determine if routine admission to the ICU is necessary for patients undergoing coil embolization of an unruptured intracranial aneurysm. We further sought to determine whether certain demographics, medical comorbidities, procedure details, or aneurysm characteristics may predispose a patient to a postoperative complication. We also aimed to evaluate the potential cost savings if admission to a step-down or telemetry unit was used rather than ICU admission.

\section{METHODS}

\section{Study design}

A retrospective cohort study was conducted of all patients undergoing treatment of an unruptured intracranial aneurysm with coil embolization between 1 January 2005 and 1 February 2012. This patient list was cross-referenced with operative reports in the medical record to confirm that coil embolization was performed and that no aneurysms were treated with newer technologies such as flow diversion or inflow disruption. Our institutional review board approved this study.

\section{Variables and complications}

Patient demographics, comorbidities, and procedural characteristics abstracted from the medical 
record included age, sex, active tobacco use, presence of diabetes mellitus, obesity (body mass index $>30 \mathrm{~kg} / \mathrm{m}^{2}$ ), hypertension, hyperlipidemia, hypercoagulability (hereditary thrombophilia, recent history of deep venous thrombosis or pulmonary embolus, known active malignancy, pregnancy), coronary artery disease, size of the treated aneurysm, bifurcation aneurysm, balloon or stent use during coiling, intraoperative rupture, and post-procedural aspirin (ASA) or clopidogrel therapy. Neurologic and medical complications were reviewed and any resulting intervention—-medical or surgical—was noted.

\section{Description of procedure}

All patients were started on a dual antiplatelet regimen 7 days prior to the procedure consisting of $81 \mathrm{mg}$ ASA and $75 \mathrm{mg}$ clopidogrel daily. Beginning in 2007, platelet inhibition was assessed with the VerifyNow (VN) ASA and VN P2Y12 assays (Accumetrics, San Diego, California, USA) in ASA reaction units and P2Y12 reaction units (PRU). Patients were considered responsive if the ASA reaction units were $\leq 550$ and PRU $\leq 237$. Non-responders were given additional ASA or clopidogrel until they responded. If no response was present, patients were placed on ticlopidine, prasugrel, or ticagrelor at the discretion of the neurointerventionalist. Patients were required to be responders prior to an intervention. Dual-trained endovascular neurosurgeons and fellowship-trained neurointerventional radiologists performed all the procedures. All procedures were performed under general anesthesia. Intraoperative neuromonitoring was used at the discretion of the treating clinician. Patients were administered IV heparin to maintain an activated clotting time between 250 and $300 \mathrm{~s}$, or $2.5 \times$ the baseline value. Arterial access was achieved in the standard fashion under ultrasound guidance and either primary coiling, balloon-assisted coiling, or stent-assisted coiling was performed to achieve obliteration of the aneurysm. No patients in the cohort underwent treatment of the aneurysm with newer technologies such as flow diversion or inflow disruption. No patients in the cohort received a glycoprotein IIb/IIIa receptor antagonist during or after the procedure. At the end of the procedure, the heparin dose was not reversed with protamine. Hemostasis was obtained at the arteriotomy site at the end of the procedure with a vascular closure device (6 Fr Angio-Seal; St Jude's Medical, Minnetoka, Minnesota, USA). All patients were admitted to the neurosurgical ICU for postoperative care under the direction of a neurointensivist.

\section{Outcomes of interest}

The primary outcome of interest was occurrence of a postoperative neurologic change attributable to the endovascular procedure with subsequent acute change in patient management. The secondary outcome of interest was the occurrence of any postoperative neurologic or medical complication during the patient's hospitalization.

\section{Statistical analysis}

Simple rates were calculated using the number of complications and the total number of procedures. Univariate or multivariate analysis was performed to identify predictors of post-procedural neurologic complication. A second analysis was performed to identify predictors of any post-procedural complications. In both cases a multivariate regression model was performed based on backward selection from factors identified to have at least marginal significance $(\mathrm{p} \leq 0.10)$ on univariate analysis. Statistical significance in the multivariate regression was assigned at $\mathrm{p}<0.05$.

\section{Cost analysis}

Average cost per patient per night in the neurosurgical ICU, a step-down unit with invasive hemodynamic monitoring, or a telemetry unit without the presence of invasive hemodynamic monitoring was queried from the hospital billing department. Given existing agreements between the hospital and its insurers, we are unable to report the absolute costs. However, percent differences between all three levels of care were calculated and reported.

\section{RESULTS}

During the study period 311 intracranial aneurysms in 311 patients were treated with conventional endovascular technology in an elective fashion. There were 247 women and 64 men. The average patient age at time of treatment was 57.7 years (range 12-79 years). One hundred and ninety aneurysms $(61.1 \%)$ were treated with coiling alone, $13(4.2 \%)$ were treated with balloon-assisted coiling, and 108 (34.7\%) were treated with stent-assisted coiling. A total of $20(6.4 \%)$ post-procedural complications were reported. Eleven of these complications were neurologic and associated with the endovascular procedure (3.5\%); five of these patients suffered a permanent neurologic deficit (1.6\%). The remainder of the complications included retroperitoneal hematomas $(n=4 ; 1.3 \%)$, delirium $(n=2 ; 0.6 \%)$, seizure $(\mathrm{n}=1 ; 0.3 \%)$, aspiration after extubation $(\mathrm{n}=1 ; 0.3 \%)$, and neck hematoma $(\mathrm{n}=1 ; 0.3 \%)$. Of the 11 patients who experienced a neurologic complication, four patients had known intraoperative complications (3 intraoperative ruptures and 1 with recognized herniation of coils into parent vessel) and three had aneurysms $>2 \mathrm{~cm}$ treated. Furthermore, in the group with neurologic complications but an uncomplicated intraoperative course, only two cases had neurologic changes discovered from frequent neurologic checks in the ICU and treatment was altered in only one case (an aneurysm $>2 \mathrm{~cm}$ ). No patient with an aneurysm $<2 \mathrm{~cm}$ who had an uncomplicated operative course had neurologic changes found during the ICU admission, and care was not altered in any of these cases. The neurologic complications encountered in our cohort and the characteristics of patients experiencing complications are summarized in tables 1 and 2.

Initial regression analysis of the primary outcome of interest identified female sex, hypercoagulability, aneurysm size $>2 \mathrm{~cm}$, and intraoperative rupture as potential predictors of a postoperative neurologic complication. Modified multivariate regression analysis including these potential predictors showed statistical significance for female sex $(p=0.028)$, hypercoagulability ( $p=0.021)$, aneurysm size $>2 \mathrm{~cm}(p=0.003)$, and intraoperative rupture $(\mathrm{p}<0.001)$ as predictors of a post-procedural neurologic complication. Results of the regression analysis of the primary outcome of interest are summarized in table 3 .

Initial regression analysis of the secondary outcome of interest identified female sex, hypertension, hypercoagulability, aneurysm size $>2 \mathrm{~cm}$, and intraoperative rupture as potential predictors of any post-procedural complication. Modified multivariate regression analysis including these potential predictors showed statistical significance for hypercoagulability $(\mathrm{p}=0.046)$, aneurysm size $>2 \mathrm{~cm} \quad(p=0.001)$, and intraoperative rupture $(\mathrm{p}<0.001)$ as predictors of any post-procedural complication. Female sex $(p=0.065)$ and hypertension $(p=0.133)$ were not statistically significant predictors in the modified analysis. Results of the regression analysis of the secondary outcome of interest are summarized in table 4 . 
Hemorrhagic stroke

Table 1 Patient cohort with neurologic complications

\begin{tabular}{|c|c|c|c|c|c|c|}
\hline $\begin{array}{l}\text { Patient } \\
\text { no }\end{array}$ & Aneurysm location & Neurologic finding & $\begin{array}{l}\text { Date of } \\
\text { neurologic } \\
\text { change }\end{array}$ & Complication & Intervention taken & Intraprocedural issues \\
\hline 1 & $\begin{array}{l}\text { Superior } \\
\text { hypophyseal }\end{array}$ & $\begin{array}{l}\text { Worsening ipsilateral visual } \\
\text { acuity }\end{array}$ & POD 1 & $\begin{array}{l}\text { None; transient } \\
\text { symptoms }\end{array}$ & Decadron & Large aneurysm, recoiling \\
\hline 2 & Ophthalmic & $\begin{array}{l}\text { Pronator drift noted after } \\
\text { cessation of heparin/dextran } \\
\text { drips }\end{array}$ & POD 1 & $\begin{array}{l}\text { TIA; no } \\
\text { permanent deficit }\end{array}$ & $\begin{array}{l}\text { Resumption of heparin/ } \\
\text { dextran drips } \times 24 \text { hours }\end{array}$ & None \\
\hline 3 & $\begin{array}{l}\text { Vertebral V4 } \\
\text { segment (sidewall) }\end{array}$ & $\begin{array}{l}\text { Left cranial nerve VI and VII } \\
\text { palsy noted after procedure }\end{array}$ & POD 0 & Brainstem stroke & None & None \\
\hline 4 & Basilar apex & $\begin{array}{l}\text { Hemianopsia noted after } \\
36 \text { hours post-op }\end{array}$ & POD 2 & Cortical stroke & $\begin{array}{l}\text { Resumption of heparin/ } \\
\text { dextran drips } \times 24 \text { hours }\end{array}$ & None \\
\hline 5 & Basilar apex & $\begin{array}{l}\text { Decreased hemibody } \\
\text { sensation }\end{array}$ & POD 2 & $\begin{array}{l}\text { Small thalamic } \\
\text { stroke }\end{array}$ & None & $\begin{array}{l}\text { Aneurysm }>2 \mathrm{~cm}, 3 \mathrm{rd} \text { trimester } \\
\text { pregnancy }\end{array}$ \\
\hline 6 & Ophthalmic & Left hemiplegia, neglect & POD 0 & Cortical stroke & $\begin{array}{l}\text { Angiography, } \\
\text { thrombolysis }\end{array}$ & Aneurysm $>2 \mathrm{~cm}$ \\
\hline 7 & $\begin{array}{l}\text { Posterior } \\
\text { communicating } \\
\text { artery }\end{array}$ & Quadrantanopia & POD 0 & $\begin{array}{l}\text { TIA; no } \\
\text { permanent deficit }\end{array}$ & $\begin{array}{l}\text { None; continuation of } \\
\text { heparin/dextran drips }\end{array}$ & $\begin{array}{l}\text { Herniation of coil loops into } \\
\text { parent vessel necessitating stent } \\
\text { placement }\end{array}$ \\
\hline 8 & Ophthalmic & $\begin{array}{l}\text { Aphasia noted after } \\
\text { cessation of heparin/dextran } \\
\text { drips }\end{array}$ & POD 1 & $\begin{array}{l}\text { TIA; no } \\
\text { permanent deficit }\end{array}$ & $\begin{array}{l}\text { Heparin bolus, } \\
\text { resumption of heparin/ } \\
\text { dextran drips }\end{array}$ & None \\
\hline 9 & Basilar apex & Hyperemesis & POD 0 & None & None & Intraoperative rupture \\
\hline 10 & Ophthalmic & Hemiparesis, neglect & POD 0 & Cortical stroke & Supportive stroke care & Intraoperative vessel perforation \\
\hline 11 & Basilar apex & Coma, moribund state & POD 0 & $\begin{array}{l}\text { Devastating } \\
\text { hemorrhage }\end{array}$ & Withdrawal of care & Intraoperative rupture \\
\hline
\end{tabular}

POD, postoperative day; TIA, transient ischemic attack.

Table 2 Characteristics of patient cohort with complications

\begin{tabular}{|c|c|c|c|c|c|c|c|c|c|c|c|c|}
\hline $\begin{array}{l}\text { Patient } \\
\text { no }\end{array}$ & $\begin{array}{l}\text { Aneurysm } \\
\text { location }\end{array}$ & $\begin{array}{l}\text { Aneurysm } \\
\text { size }(\mathrm{mm})\end{array}$ & $\begin{array}{l}\text { Age } \\
\text { (years) }\end{array}$ & HTN & Diabetes & Hyper-lipidemia & $\begin{array}{l}\text { Tobacco } \\
\text { use }\end{array}$ & $\begin{array}{l}\text { Coronary } \\
\text { artery } \\
\text { disease }\end{array}$ & $\begin{array}{l}\text { Antiplatelet } \\
\text { used }\end{array}$ & $\begin{array}{l}\text { Stent } \\
\text { use }\end{array}$ & $\begin{array}{l}\text { Intra-procedural } \\
\text { complication }\end{array}$ & $\begin{array}{l}\text { Aneurysm } \\
\text { size }>2 \mathrm{~cm}\end{array}$ \\
\hline 1 & $\begin{array}{l}\text { Superior } \\
\text { hypophyseal }\end{array}$ & $16 \times 13 \times 10$ & $50 \mathrm{~s}$ & $Y$ & $\mathrm{~N}$ & $Y$ & $\mathrm{~N}$ & N & $\begin{array}{l}\text { ASA } \\
\text { +clopidogrel }\end{array}$ & $Y$ & N & N \\
\hline 2 & Ophthalmic & $5 \times 7 \times 7$ & $50 \mathrm{~s}$ & $\mathrm{~N}$ & $\mathrm{~N}$ & N & N & N & $\begin{array}{l}\text { ASA } \\
+ \text { clopidogrel }\end{array}$ & N & N & $\mathrm{N}$ \\
\hline 3 & $\begin{array}{l}\text { Vertebral } \\
\text { sidewall }\end{array}$ & $10 \times 11 \times 10$ & $70 \mathrm{~s}$ & N & $\mathrm{N}$ & N & $Y$ & N & $\begin{array}{l}\text { ASA } \\
+ \text { clopidogrel }\end{array}$ & $Y$ & N & N \\
\hline 4 & Basilar apex & $8 \times 6 \times 5$ & $70 \mathrm{~s}$ & $Y$ & $\mathrm{~N}$ & $Y$ & Y & $N$ & $\begin{array}{l}\text { ASA } \\
+ \text { clopidogrel }\end{array}$ & N & N & N \\
\hline 5 & Basilar apex & $30 \times 28 \times 22$ & $20 \mathrm{~s}$ & $\mathrm{~N}$ & $\mathrm{~N}$ & N & N & N & ASA alone & Y & N & Y \\
\hline 6 & Ophthalmic & $22 \times 16 \times 14$ & $60 \mathrm{~s}$ & $Y$ & N & $Y$ & $Y$ & N & $\begin{array}{l}\text { ASA } \\
+ \text { clopidogrel }\end{array}$ & N & N & $Y$ \\
\hline 7 & $\begin{array}{l}\text { Posterior } \\
\text { communicating } \\
\text { artery }\end{array}$ & $8 \times 6 \times 5$ & $50 \mathrm{~s}$ & $Y$ & N & N & $Y$ & Y & $\begin{array}{l}\text { ASA } \\
\text { +clopidogrel }\end{array}$ & $Y$ & $Y$ & $\mathrm{~N}$ \\
\hline 8 & Ophthalmic & $4 \times 4 \times 5$ & $70 \mathrm{~s}$ & Y & $\mathrm{N}$ & $\mathrm{N}$ & Y & $\mathrm{N}$ & $\begin{array}{l}\text { ASA } \\
+ \text { clopidogrel }\end{array}$ & $Y$ & N & $\mathrm{N}$ \\
\hline 9 & Basilar apex & $5 \times 4 \times 3$ & $40 \mathrm{~s}$ & $Y$ & $\mathrm{~N}$ & $\mathrm{~N}$ & Y & $\mathrm{N}$ & $\begin{array}{l}\text { ASA } \\
+ \text { clopidogrel }\end{array}$ & $Y$ & Y & $\mathrm{N}$ \\
\hline 10 & Ophthalmic & $2 \times 3 \times 4$ & $40 \mathrm{~s}$ & Y & $\mathrm{N}$ & N & $Y$ & $\mathrm{~N}$ & $\begin{array}{l}\text { ASA } \\
\text { +clopidogrel }\end{array}$ & N & $Y$ & $\mathrm{~N}$ \\
\hline 11 & Basilar apex & $21 \times 14 \times 16$ & $70 \mathrm{~s}$ & $Y$ & $\mathrm{~N}$ & $Y$ & Y & N & $\begin{array}{l}\text { ASA } \\
+ \text { clopidogrel }\end{array}$ & Y & Y & Y \\
\hline
\end{tabular}

ASA, aspirin; HTN, hypertension.

Our cost analysis demonstrated that patients admitted to a step-down unit with invasive line monitoring had a cost savings of $32 \%$ per day compared with ICU admission. Savings increased to $57 \%$ per day if patients were admitted to a telemetry unit without invasive monitoring capabilities.

\section{DISCUSSION}

Elective coil embolization of unruptured intracranial aneurysms is associated with a low risk of post-procedural complications. Our series demonstrated that patients with a history of hypercoagulability, an aneurysm $>2 \mathrm{~cm}$, or an intraprocedural rupture 
Table 3 Effect of baseline and procedural characteristics on risk for post-procedural neurologic complications

\begin{tabular}{lllll}
\hline Characteristic & $\begin{array}{l}\text { Crude } \\
\text { p value }\end{array}$ & $\begin{array}{l}\text { Adjusted } \\
\text { p value }\end{array}$ & $\begin{array}{l}\text { Adjusted } \\
\text { OR }\end{array}$ & 95\% Cl \\
\hline Female vs male & 0.013 & 0.028 & 1.06 & 1.01 to 1.11 \\
Age $>65$ years & 0.201 & - & - & - \\
Obesity & 0.526 & - & - & - \\
Hypertension & 0.215 & - & - & - \\
$\begin{array}{l}\text { Diabetes } \\
\text { Hypercoagulable }\end{array}$ & 0.256 & - & - & - \\
Hyperlipidemia & 0.047 & 0.021 & 1.08 & 1.01 to 1.14 \\
$\begin{array}{l}\text { Coronary artery } \\
\text { disease }\end{array}$ & 0.700 & - & - & - \\
$\begin{array}{l}\text { Tobacco use } \\
\text { Aspirin therapy }\end{array}$ & 0.287 & - & - & - \\
$\begin{array}{l}\text { Clopidogrel therapy } \\
\text { Aneurysm size }\end{array}$ & 0.767 & - & - & - \\
$>$ 2 cm & 0.865 & - & - & - \\
$\begin{array}{l}\text { Bifurcation } \\
\text { aneurysm }\end{array}$ & 0.002 & 0.003 & 1.18 & 1.06 to 1.31 \\
$\begin{array}{l}\text { Balloon-assisted } \\
\text { coiling }\end{array}$ & 0.755 & - & - & - \\
$\begin{array}{l}\text { Stent-assisted } \\
\text { coiling }\end{array}$ & 0.313 & - & - & - \\
$\begin{array}{l}\text { Intraoperative } \\
\text { rupture }\end{array}$ & $<0.001$ & $<0.001$ & 2.49 & - \\
\hline & & & & - \\
\hline
\end{tabular}

were more likely to develop a postoperative complication (neurologic or otherwise), and closer post-procedural monitoring in the ICU is warranted in these cases. Patients without a complex neurologic or medical history, with a small aneurysm, or with an uncomplicated procedural course should be considered for admission to a step-down unit or telemetry bed since post-procedural complications are uncommon in these cases. Our cost analysis demonstrated that significant cost savings could be achieved with such a strategy.

Routine ICU admission following coil embolization of elective unruptured intracranial aneurysms is an unproven practice that persists despite advances in medical therapy and endovascular technology. Two smaller cohort analyses support our findings and suggest that it is an unnecessary practice. ${ }^{11} 12 \mathrm{~A}$ prospective study of 200 patients by Burrows et al showed that a risk stratification strategy could be used safely and successfully to determine which patients require post-procedural ICU admission. ${ }^{12}$ The authors experienced only one change in admission status in a total of 131 procedures. Risk factors predictive of a complicated post-procedural course included older age, intraprocedural complications, medical or neurologic comorbidities, complex aneurysm, or the use of a stent. ${ }^{12-15}$ Our study showed similar findings, with female sex, hypercoagulability, aneurysm size $>2 \mathrm{~cm}$, and intraoperative rupture as predictors of a postoperative neurologic complication. When these factors are present, special consideration should be given to closer monitoring and potential ICU admission.

Richards et al, in a retrospective study of 127 patients, analyzed whether a step-down unit could be a safe and costeffective alternative to the ICU for patients with uncomplicated neurointerventional procedures. The authors included 74 cases of aneurysm coiling and 28 cases of stent-assisted coiling in their cohort; however, they did not analyze factors that may make the patient more likely to need an ICU bed. They showed a mean cost saving of $15 \%$ for admission to a step-down unit versus an ICU. We found better cost savings; however, reimbursement varies based on geographic location and the type of hospital.

An alternative strategy to ICU admission could be an extended period of close monitoring in the immediate postprocedural period of up to 4 hours. In previous reports the vast majority of peri-procedural complications from elective endovascular aneurysm therapy occurred either during the procedure or within the first 4 hours following the procedure. ${ }^{10} 1216$ Post-anesthesia recovery units provide low patient-to-nurse ratios (often $1: 1$ or $1: 2$ ) and invasive monitoring capabilities, allowing for rapid identification and management of potential complications. After the immediate post-procedural period, admission to a step-down unit, telemetry unit, floor bed, or possibly a same-day discharge should be considered in uncomplicated cases. Although patient safety is the foremost consideration in the post-procedural care of neurologic patients, the cost of care must also be assessed. ICU care remains one of

Table 4 Effect of baseline and procedural characteristics on risk for any post-procedural complication

\begin{tabular}{|c|c|c|c|c|}
\hline Characteristic & Crude $p$ value & Adjusted $\mathrm{p}$ value & Adjusted OR & $95 \% \mathrm{Cl}$ \\
\hline Female vs male & 0.068 & 0.065 & 1.06 & 1.00 to 1.13 \\
\hline Age $>65$ years & 0.942 & - & - & - \\
\hline Obesity & 0.591 & - & - & - \\
\hline Hypertension & 0.100 & 0.133 & 1.04 & 0.99 to 1.10 \\
\hline Diabetes & 0.124 & - & - & - \\
\hline Hypercoagulable & 0.053 & 0.046 & 1.08 & 1.00 to 1.17 \\
\hline Hyperlipidemia & 0.771 & - & - & - \\
\hline Coronary artery disease & 0.724 & - & - & - \\
\hline Tobacco use & 0.930 & - & - & - \\
\hline Aspirin therapy & 0.864 & - & - & - \\
\hline Clopidogrel therapy & 0.948 & - & - & - \\
\hline Aneurysm size $>2 \mathrm{~cm}$ & 0.001 & 0.001 & 1.26 & 1.10 to 1.44 \\
\hline Bifurcation aneurysm & 0.955 & - & - & - \\
\hline Balloon-assisted coiling & 0.154 & - & - & - \\
\hline Stent-assisted coiling & 0.239 & - & - & - \\
\hline Intraoperative rupture & $<0.001$ & $<0.001$ & 2.35 & 1.82 to 3.05 \\
\hline
\end{tabular}


the largest contributors to healthcare costs in the USA. ${ }^{17}$ Our cost analysis demonstrated cost savings up to $57 \%$ with postprocedural admission to a telemetry unit rather than an ICU. The savings we found are in line with other reports in the literature. ${ }^{11}$

This study is limited by its retrospective nature and the relatively small number of cases. Our results are nevertheless intriguing, and add to the growing body of evidence that contradicts routine ICU admission following uncomplicated elective endovascular cerebral aneurysm treatment. Larger prospective and randomized studies are needed to further corroborate our findings.

\section{CONCLUSIONS}

Neurologic complications following elective treatment of unruptured intracranial aneurysms are rare, suggesting that routine ICU admission post-procedure may not be necessary. Female sex, a history of hypercoagulability, aneurysm size $>2 \mathrm{~cm}$, or an intraprocedural rupture are more likely to result in postoperative complications for which ICU monitoring is warranted. Cost analysis demonstrates that significant cost savings could be achieved with such a strategy.

Contributors All authors contributed to writing, data gathering, data analysis, manuscript review and approval for submission.

Competing interests None declared.

Ethics approval Ethics approval was obtained from the University of Michigan Institutional Review Board.

Provenance and peer review Not commissioned; externally peer reviewed.

\section{REFERENCES}

1 Guglielmi G, Vinuela F, Dion J, et al. Electrothrombosis of saccular aneurysms via endovascular approach. Part 2: preliminary clinical experience. J Neurosurg $1991 ; 75: 8-14$
2 Fiehler J, Ries T. Prevention and treatment of thromboembolism during endovascular aneurysm therapy. Klin Neuroradiol 2009;19:73-81.

3 Jabbour $\mathrm{P}$, Koebbe $\mathrm{C}$, Veznedaroglu $\mathrm{E}$, et al. Stent-assisted coil placement for unruptured cerebral aneurysms. Neurosurg Focus 2004;17:E10.

4 Kang HS, Han MH, Kwon BJ, et al. Is clopidogrel premedication useful to reduce thromboembolic events during coil embolization for unruptured intracranial aneurysms? Neurosurgery 2010;67:1371-6.

5 Cavaliere F, Conti G, Costa R, et al. Intensive care after elective surgery: a survey on 30-day postoperative mortality and morbidity. Minerva Anestesiol 2008;74:459-68.

6 Pearse RM, Harrison DA, James P, et al. Identification and characterisation of the high-risk surgical population in the United Kingdom. Crit Care 2006;10:R81.

7 Teplick R, Caldera DL, Gilbert JP, et al. Benefit of elective intensive care admission after certain operations. Anesth Analg 1983;62:572-7.

8 Beauregard CL, Friedman WA. Routine use of postoperative ICU care for elective craniotomy: a cost-benefit analysis. Surg Neurol 2003;60:483-9.

9 Bui JQ, Mendis RL, van Gelder JM, et al. Is postoperative intensive care unit admission a prerequisite for elective craniotomy? J Neurosurg 2011;115:1236-41.

10 Niskanen M, Koivisto T, Rinne J, et al. Complications and postoperative care in patients undergoing treatment for unruptured intracranial aneurysms. J Neurosurg Anesthesiol 2005;17:100-5.

11 Richards BF, Fleming JB, Shannon CN, et al. Safety and cost effectiveness of step-down unit admission following elective neurointerventional procedures. J Neurointerv Surg 2012;4:390-2.

12 Burrows $\mathrm{AM}$, Rabinstein $\mathrm{AA}, \mathrm{Cloft} \mathrm{HJ}$, et al. Are routine intensive care admissions needed after endovascular treatment of unruptured aneurysms? AJNR Am J Neuroradiol 2013;34:2199-201.

13 Khosla A, Brinjikji W, Cloft $\mathrm{H}$, et al. Age-related complications following endovascular treatment of unruptured intracranial aneurysms. AJNR Am Neuroradiol 2012;33:953-7.

14 Petr O, Brinjikji W, Cloft $\mathrm{H}$, et al. Current trends and results of endovascular treatment of unruptured intracranial aneurysms at a single institution in the flow-diverter era. AJNR Am J Neuroradiol 2016;37:1106-13.

15 Shamim F, Asghar A, Karam K. Frequency of intensive care unit admission after elective interventional neuroradiological procedures under general anesthesia in a tertiary care hospital. Saudi J Anaesth 2015;9:23-6.

16 Arias EJ, Patel B, Cross DT III, et al. Timing and nature of in-house postoperative events following uncomplicated elective endovascular aneurysm treatment. J Neurosurg 2014;121:1063-70.

17 Halpern NA, Pastores SM. Critical care medicine in the United States 2000-2005 an analysis of bed numbers, occupancy rates, payer mix, and costs. Crit Care Med 2010;38:65-71. 